\title{
Association of overweight and obesity with health status, weight management, and exercise behaviors among individuals with type 2 diabetes mellitus or with cardiometabolic risk factors
}

\author{
James R Gavin, III' \\ Helena W Rodbard ${ }^{2}$ \\ Kathleen M Fox ${ }^{3}$ \\ Susan Grandy ${ }^{4}$ \\ for the SHIELD Study \\ Group \\ 'Emory University School of Medicine, \\ Atlanta, GA, USA; ${ }^{2}$ Endocrine \\ and Metabolic Consultants, Rockville, \\ MD, USA; ${ }^{3}$ Strategic Healthcare \\ Solutions, LLC, Monkton, MD, USA \\ ${ }^{4}$ AstraZeneca LP, Wilmington, DE, \\ USA
}

Correspondence: Kathleen M Fox PO Box 543, Monkton, MD 2I I I I, USA

$\mathrm{Tel}+\mathrm{I} 4436902198$

Fax + I 4103578018

Email kathyfox@comcast.net
Objectives: This investigation evaluated the role of obesity in health status and behaviors for weight management and exercise among individuals with type 2 diabetes mellitus (T2DM) or cardiometabolic risk factors.

Methods: Self-reported health status, exercise behaviors, and weight management were assessed in the SHIELD study for respondents with T2DM or high risk (HR) for diabetes (ie, $\geq 3$ of the following: abdominal obesity, body mass index [BMI] $\geq 28 \mathrm{~kg} / \mathrm{m}^{2}$, self-reported diagnosis of dyslipidemia, hypertension, or history of cardiovascular disease). Respondents were stratified into three BMI categories: $<25 \mathrm{~kg} / \mathrm{m}^{2}$ (underweight or normal weight), $25.0-29.9 \mathrm{~kg} / \mathrm{m}^{2}$ (overweight), and $\geq 30 \mathrm{~kg} / \mathrm{m}^{2}$ (obese), with comparisons made using analysis of variance. Comparisons between T2DM and HR were made using chi-square tests.

Results: T2DM $(\mathrm{n}=3,918)$ and HR $(\mathrm{n}=5,464)$ groups were similar for age (mean $=59$ years), race ( $\geq 85 \%$ white), and obesity. Overweight (31\%) or obese T2DM (18\%) respondents were significantly less likely to report excellent health compared with overweight or obese HR respondents ( $42 \%$ and $30 \%$, respectively), $\mathrm{p}<0.001$. There were no differences between T2DM and HR groups for exercise behaviors. More obese respondents (20\% T2DM, 21\% HR) were "contemplating exercising", and fewer (21\%-23\%) were currently "exercising regularly" compared with overweight and normal weight respondents, $\mathrm{p}<0.001$. More obese respondents (78\% T2DM, 83\% HR) attempted weight management than normal $(28 \%-35 \%)$ or overweight $(57 \%-61 \%)$ respondents, $\mathrm{p}<0.001$.

Conclusions: Obesity was negatively associated with self-perception of current health, exercising regularly, and weight maintenance for those with or at risk for diabetes.

Keywords: overweight, obesity, type 2 diabetes mellitus, exercise, weight management

\section{Introduction}

Health behaviors of individuals with or at risk for type 2 diabetes mellitus and those with a high body mass index (BMI) continue to be important drivers of health outcomes from a public health perspective. ${ }^{1,2}$ The burden of diabetes is substantial, including increased mortality, higher risk for cardiovascular disease (CVD), caregiver burden and economic costs approximating $\$ 174$ billion annually., ${ }^{2,3}$ The burden of being overweight or obese, whether or not it is coexistent with type 2 diabetes mellitus, is equally significant. Using the National Health and Nutrition Examination Survey (NHANES) 1999-2002, the Centers for Disease Control and Prevention estimated that $65 \%$ of the US population is overweight or obese, representing a $16 \%$ increase over estimates obtained from NHANES 1988-1994. ${ }^{4}$ Overall, employers and privately insured individuals spent $\$ 36.5$ billion on obesity-linked illnesses in 2002, up from an inflation-adjusted $\$ 3.6$ billion in $1987 . .^{5}$ 
While the societal impact of diabetes and obesity is substantial, both remain largely self-managed conditions. Therefore, patient characteristics, such as health-related attitudes and behaviors, are important to achieving good health outcomes. Given the patient-level responsibility for managing diabetes, it is important to understand how various aspects of health attitudes and behaviors interact to drive both positive and negative health outcomes. Previous studies have shown that patient attitudes about overall health are predictive of future levels of functioning and mortality. ${ }^{6}$ Older people who assessed their global health, self-care ability, and physical activity less favorably were more likely to experience poor physical functioning and increased mortality. ${ }^{6}$ Evidence from the Study to Help Improve Early evaluation and management of risk factors Leading to Diabetes (SHIELD) showed that individuals with type 2 diabetes or cardiometabolic risk factors were aware of the behaviors necessary to maintain or improve their health but were not exhibiting these behaviors in their daily lives. ${ }^{7}$

A better understanding of the interaction of individuals' health status and behaviors and obesity can lead to increased opportunities for intervention and may enhance the likelihood for improved clinical outcomes. The objective of this study was to evaluate the association between health status and behaviors and obesity among individuals with type 2 diabetes mellitus and those at high risk for diabetes mellitus in order to understand whether obesity influenced the association between diabetes mellitus and health status and behaviors toward weight management and exercise.

\section{Methods}

\section{SHIELD survey}

SHIELD included an initial screening phase to identify cases of interest in the general population and a baseline survey to follow up identified cases with a questionnaire about health status, health knowledge and attitudes, and current behaviors and treatments. A detailed description of the SHIELD methodology has been published previously..$^{7-10}$

The screening survey was mailed on April 1, 2004, to a stratified random sample of 200,000 US households, representative of the US population for geographic residence, household size and income, and age of head of household, ${ }^{11}$ identified by the Taylor Nelson Sofres National Family Opinion (TNS NFO) panel (Greenwich, CT). The head of household provided responses to the screening survey for up to four adult (aged $\geq 18$ years) household members. A response rate (computed as completed surveys/surveys mailed) of $63.7 \%$ was obtained from 127,420 households (containing 211,097 adults).
Based on the screening survey, respondents without diabetes mellitus were classified as high risk or low risk for diabetes using five cardiometabolic risk factors that were identified through epidemiological studies and national guidelines: ${ }^{12,13} 1$ ) abdominal obesity (defined as waist circumference $\geq 97 \mathrm{~cm}$ for men, $\geq 89 \mathrm{~cm}$ for women); 2) BMI $\geq 28 \mathrm{~kg} / \mathrm{m}^{2}$; 3) reported diagnosis of cholesterol problems of any type (ie, dyslipidemia); 4) reported diagnosis of high blood pressure (ie, hypertension); and 5) history of cardiovascular disease (defined as reported heart disease/ heart attack, narrow or blocked arteries, stroke, heart bypass surgery, or angioplasty/stents to clear arteries). Respondents with $\geq 3$ risk factors were classified as high risk, and respondents with 0-2 risk factors were classified as low risk.

The baseline survey was mailed in September and October 2004 to a representative sample of individuals $(n=22,001)$ who were identified in the screening survey as having type 1 diabetes mellitus, type 2 diabetes mellitus, or $0-5$ risk factor levels. Each respondent group was balanced to be representative of that population for age, gender, geographic region, household size and income for the US population, and then a random sample from each group was selected and sent the baseline survey. A response rate of $71.8 \%$ was obtained $(\mathrm{n}=15,794)$. We certify that all applicable institutional and governmental regulations concerning the ethical use of human volunteers were followed during this research.

\section{Study measures}

Self-reported health status was measured by two questions. Survey respondents were asked their level of agreement with the statement: "My health is excellent". Respondents who "strongly agree" or "somewhat agree" that their health was excellent were hypothesized to be more likely to have healthy behaviors (exercise regularly, manage weight) and were included in the analyses. Respondents were also asked, "Overall, how concerned are you that your health problems might get worse over time". Respondents who indicated "moderately concerned" or "very concerned" were hypothesized to be more motivated to do healthy behaviors so their health would not worsen.

Exercise behaviors were reported as "exercising regularly for at least the past six months" or "not currently exercising regularly but considering starting to exercise regularly in the next six months". These two exercise categories were analyzed to explore actual good exercise behavior (ie, regular exercise) as well as the intention or contemplation of exercise. Weight management was assessed by a series of questions over different time frames. Respondents were asked if they had "tried to lose weight during the past 12 months," "tried 
to keep from gaining weight in the past 12 months," "actively tried to lose weight in the past month," "actively tried not to gain weight in the past month," "seriously considered trying to lose weight to reach goal in the next six months," and "maintained desired weight for more than six months".

BMI was stratified into three categories to assess its influence on health attitudes and behaviors. BMI $<25.0 \mathrm{~kg} / \mathrm{m}^{2}$ was classified as underweight or normal weight (about $1 \%$ of respondents were underweight with BMI $<18.5 \mathrm{~kg} / \mathrm{m}^{2}$ ), BMI between 25.0 and $29.9 \mathrm{~kg} / \mathrm{m}^{2}$ was classified as overweight, and $\mathrm{BMI} \geq 30 \mathrm{~kg} / \mathrm{m}^{2}$ was classified as obese.

\section{Statistical analysis}

Type 2 diabetes mellitus $(n=3,918)$ and high-risk $(n=5,464)$ respondent groups were included in the analysis. Comparison across BMI categories was made using analysis of variance with Fisher's least significant difference post-hoc testing. Comparisons between type 2 diabetes mellitus and highrisk groups were made using chi-square tests for pair-wise comparisons tests while applying a Bonferroni adjustment for multiple comparisons so that statistical significance was set a priori as $\mathrm{p}<0.01$.

\section{Results}

Type 2 diabetes mellitus respondents were older and had lower education and lower household income compared with high-risk respondents ( $\mathrm{p}<0.001$ for each comparison) (Table 1). There were significantly fewer whites among the type 2 diabetes mellitus respondents than among the high-risk respondents $(p<0.001)$. A large percentage of respondents were obese in both groups, but significantly more high-risk respondents $(68 \%)$ were obese than type 2 diabetes mellitus respondents $(62 \%)(\mathrm{p}<0.001)$. This difference may be due to the risk factor criteria for the high-risk group, which included abdominal circumference and BMI $\geq 28$.

\section{Health status}

Current health status differed significantly between groups; $23 \%$ of type 2 diabetes mellitus respondents agreed (strongly or somewhat) that their health was excellent, compared with $33 \%$ of high-risk respondents $(\mathrm{p}<0.001)$ (Table 1$)$. Almost three quarters (71\%) of respondents with type 2 diabetes mellitus were concerned (very or moderately) that their health problems might get worse, compared with $60 \%$ of those at high risk ( $\mathrm{p}<0.001)$ (Table 1$)$. However, being overweight or obese was significantly negatively associated with current health status and future health in both type 2 diabetes and HR groups. Individuals with diabetes mellitus who were also overweight or obese were significantly less likely to agree that their current health was excellent $(30.6 \%$ and $18.4 \%$, respectively), compared with high-risk respondents who were overweight or obese ( $41.5 \%$ and $29.9 \%$, respectively) $(\mathrm{p}<0.001)$ (Figure 1). Within the type 2 diabetes mellitus and high-risk groups, significantly fewer obese respondents agreed that their current health was excellent compared with overweight and underweight or normal weight respondents ( $p<0.001$ ), although no differences were observed between overweight and normal weight groups. Respondents with diabetes mellitus who were overweight or obese were significantly more likely to be concerned that their health problems would worsen over time (63.2\% and $76.2 \%$, respectively), compared with those who were high risk and overweight or obese $(53.2 \%$ and $62.5 \%$, respectively) $(\mathrm{p}<0.001)$ (Figure 1). Among those who were underweight or normal weight, there was no significant difference observed between type 2 diabetes mellitus and high-risk groups concerning current health state or future health status (Figure 1).

\section{Exercise}

Overall, no difference was observed between the type 2 diabetes mellitus and high-risk groups with regard to whether they were "contemplating regular exercise in the next 6 months" or who "currently exercised regularly", $p=0.48$ (Table 1). Among overweight patients, a greater proportion of high-risk respondents stated that they were contemplating exercising compared with type 2 diabetes mellitus respondents $(\mathrm{p}<0.003)$ (Figure 2$)$. There was a significant difference across BMI groups: obese respondents in both groups were significantly more likely to be thinking about exercising and significantly less likely to be engaged in regular exercise than the overweight and normal weight groups $(\mathrm{p}<0.001)$ (Figure 2$)$.

\section{Weight loss}

Diabetes status (type 2 diabetes mellitus or high risk) did not impact attempts to lose or maintain weight when controlling for BMI category for underweight or normal weight and overweight respondents (Table 2). For obese respondents, a significantly greater percentage of type 2 diabetes mellitus respondents had tried to lose or maintain weight in the past month and past 12 months compared with high-risk respondents ( $p<0.001$ ). The proportion of respondents who attempted to lose or maintain weight differed significantly across BMI category, with a significantly higher percentage of obese respondents attempting weight management $(\mathrm{p}<0.001$ for both type 2 diabetes mellitus and high risk) (Table 2). 
Table I Characteristics and health state of respondents with type 2 diabetes mellitus or high risk

\begin{tabular}{|c|c|c|}
\hline Characteristics & $\begin{array}{l}\text { Type } 2 \text { diabetes mellitus } \\
\mathrm{n}=3,918\end{array}$ & $\begin{array}{l}\text { High risk } \\
\mathrm{n}=5,464\end{array}$ \\
\hline Age, years, mean (SD) & $60.3(13.1)^{* *}$ & $59.0(14.7)$ \\
\hline Men, \% & 42 & 43 \\
\hline White, \% & $85 * *$ & 88 \\
\hline Education, \% with at least some college & $64 * *$ & 68 \\
\hline Income, $\%<\$ 40,000 /$ year & $53 * *$ & 47 \\
\hline \multicolumn{3}{|l|}{ Body mass index (BMI) category, kg/m² } \\
\hline Underweight or normal weight, $<25$ & 11 & 5 \\
\hline Overweight, 25-29.9 & 27 & 27 \\
\hline Obese, $\geq 30$ & $62 * *$ & 68 \\
\hline \multicolumn{3}{|l|}{ Health state } \\
\hline $\begin{array}{l}\text { My health is excellent, \% agree strongly or } \\
\text { agree somewhat }\end{array}$ & $23.4 * *$ & 33.3 \\
\hline $\begin{array}{l}\text { Concerned that your health might get worse } \\
\text { over time, \% very concerned or moderately } \\
\text { concerned }\end{array}$ & $\begin{array}{l}71.2 * * \\
\mathrm{n}=3,599\end{array}$ & $\begin{array}{l}59.8 \\
n=5,054\end{array}$ \\
\hline Exercise & $\mathrm{n}=3,867$ & $\mathrm{n}=5,419$ \\
\hline Currently exercise regularly, \% & 26.4 & 26.8 \\
\hline Currently exercise some, but not regularly, \% & 44.3 & 42.0 \\
\hline $\begin{array}{l}\text { Currently do not exercise, but am thinking } \\
\text { about starting, \% }\end{array}$ & 15.9 & 18.0 \\
\hline $\begin{array}{l}\text { Currently do not exercise and do not intend } \\
\text { to start, \% }\end{array}$ & 13.3 & 13.2 \\
\hline \multicolumn{3}{|l|}{ Weight management } \\
\hline Tried to lose weight in past 12 months, $\%$ & $\begin{array}{l}69.6 * \\
n=3,879\end{array}$ & $\begin{array}{l}71.5 \\
n=5,448\end{array}$ \\
\hline Tried to keep from gaining weight in past & 74.9 & 74.0 \\
\hline 12 months, $\%$ & $\mathrm{n}=3,880$ & $\mathrm{n}=5,44 \mathrm{I}$ \\
\hline $\begin{array}{l}\text { Seriously considering trying to lose weight } \\
\text { to reach goal in next } 6 \text { months, } \%\end{array}$ & $\begin{array}{l}57.3 * * \\
\mathrm{n}=3,822\end{array}$ & $\begin{array}{l}61.0 \\
n=5,375\end{array}$ \\
\hline Maintained desired weight for more than & $33.7 * *$ & 27.0 \\
\hline 6 months, \% & $\mathrm{n}=3,806$ & $n=5,331$ \\
\hline
\end{tabular}

Notes: ${ }^{*} \mathrm{p}<0.05$ and ${ }^{* *} \mathrm{p}<0.001$ for comparison of type 2 diabetes mellitus vs high-risk respondents.

For "maintaining desired weight for more than 6 months" and "seriously considering trying to lose weight to achieve weight goal," significantly fewer obese respondents, both type 2 diabetes mellitus and high risk, maintained desired weight, but a significantly higher percentage of obese respondents seriously considered trying to lose weight than underweight or normal weight and overweight respondents ( $<<0.001)$ (Table 2). Among overweight respondents who maintained desired weight, a higher percentage of respondents with type 2 diabetes mellitus maintained weight compared with the high-risk group $(\mathrm{p}<0.001)$ (Table 2).

\section{Discussion}

In the present study, independent of T2DM or HR status, BMI (ie, obesity) was strongly associated with health status and behaviors. Moving from normal weight to overweight to obese, views of current health declined and views of future health were significantly more pessimistic, whereas the stated intention or desire to lose or maintain weight and to exercise regularly was significantly stronger. Yet the percentage of respondents who currently exercised or actually maintained desired weight was lowest among the obese respondents. Thus, despite what may be appropriately directed desires for better health, the outcomes reported among obese individuals were decidedly poorer. Moreover, the health status of individuals with and at high risk for diabetes mellitus were similar, although there was an important difference in their current and future health status. Individuals with diabetes mellitus were less apt to report that their current health was excellent and more likely to expect that their health would deteriorate. 


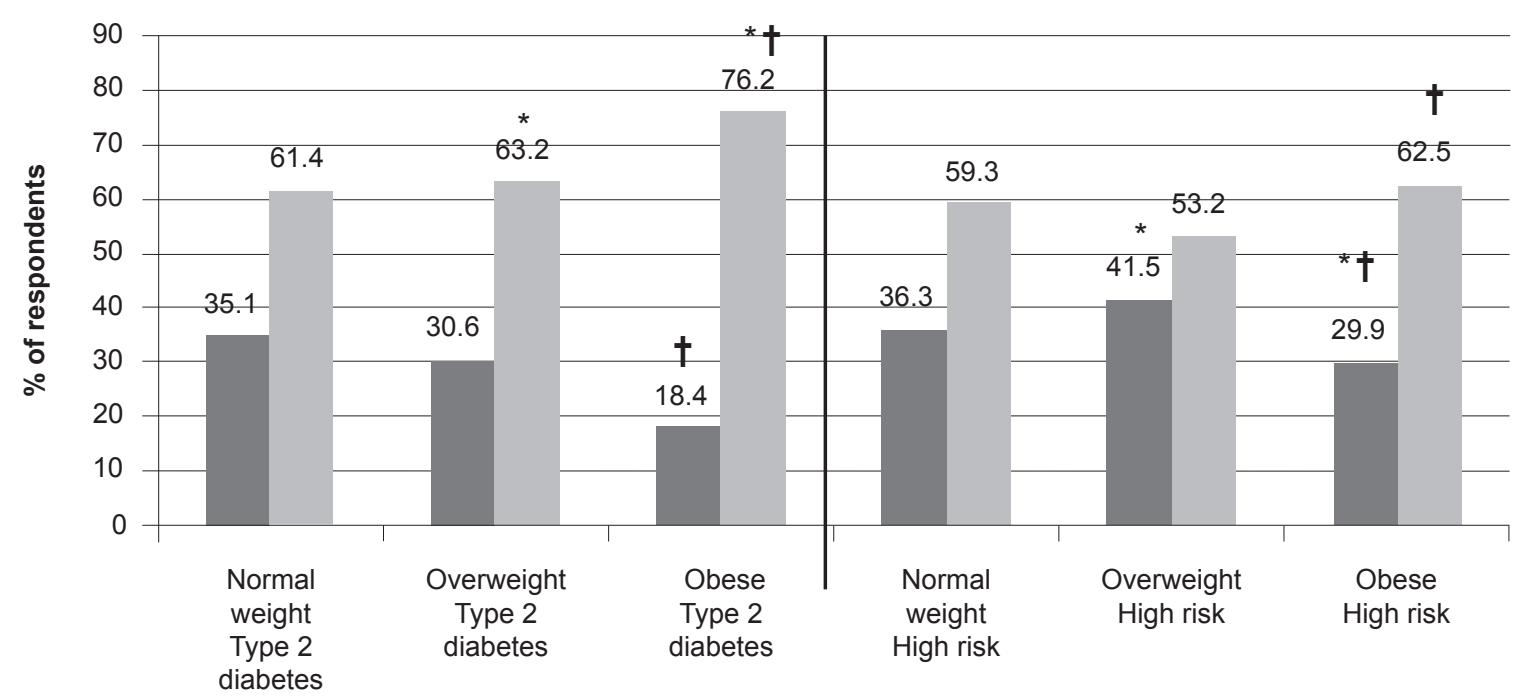

Figure I Proportion of respondents who strongly or somewhat agreed that their health was excellent or were very or moderately concerned that health problems might worsen over time, by body mass index $\left(\mathrm{BMI}, \mathrm{kg} / \mathrm{m}^{2}\right)$ category.

Notes: ${ }^{\dagger} \mathrm{p}<0.001$ for comparison across BMI categories; ${ }^{*} \mathrm{p}<0.001$ for comparison of type 2 diabetes mellitus versus high-risk respondents; Underweight/normal weight: BMI $<25.0 \mathrm{~kg} / \mathrm{m}^{2}$; overweight: BMI $25.0-29.9 \mathrm{~kg} / \mathrm{m}^{2}$; obese: BMI $\geq 30.0 \mathrm{~kg} / \mathrm{m}^{2}$.

The findings from this study have important implications. Individuals with the highest BMI and whose health status were the most negative (ie, disagree that current health is excellent, and concerned about future health) were the least likely to be able to lose weight or exercise regularly. Having diabetes mellitus slightly increased the negative association regarding current and future health, but had no effect on health behaviors with respect to exercise and weight management. The findings from the present study identified one major risk factor, obesity, for clinicians to focus upon to assist their patients in learning how to change behaviors regarding weight and exercise.

In a previous SHIELD investigation, approximately one half of type 2 diabetes mellitus and high-risk respondents

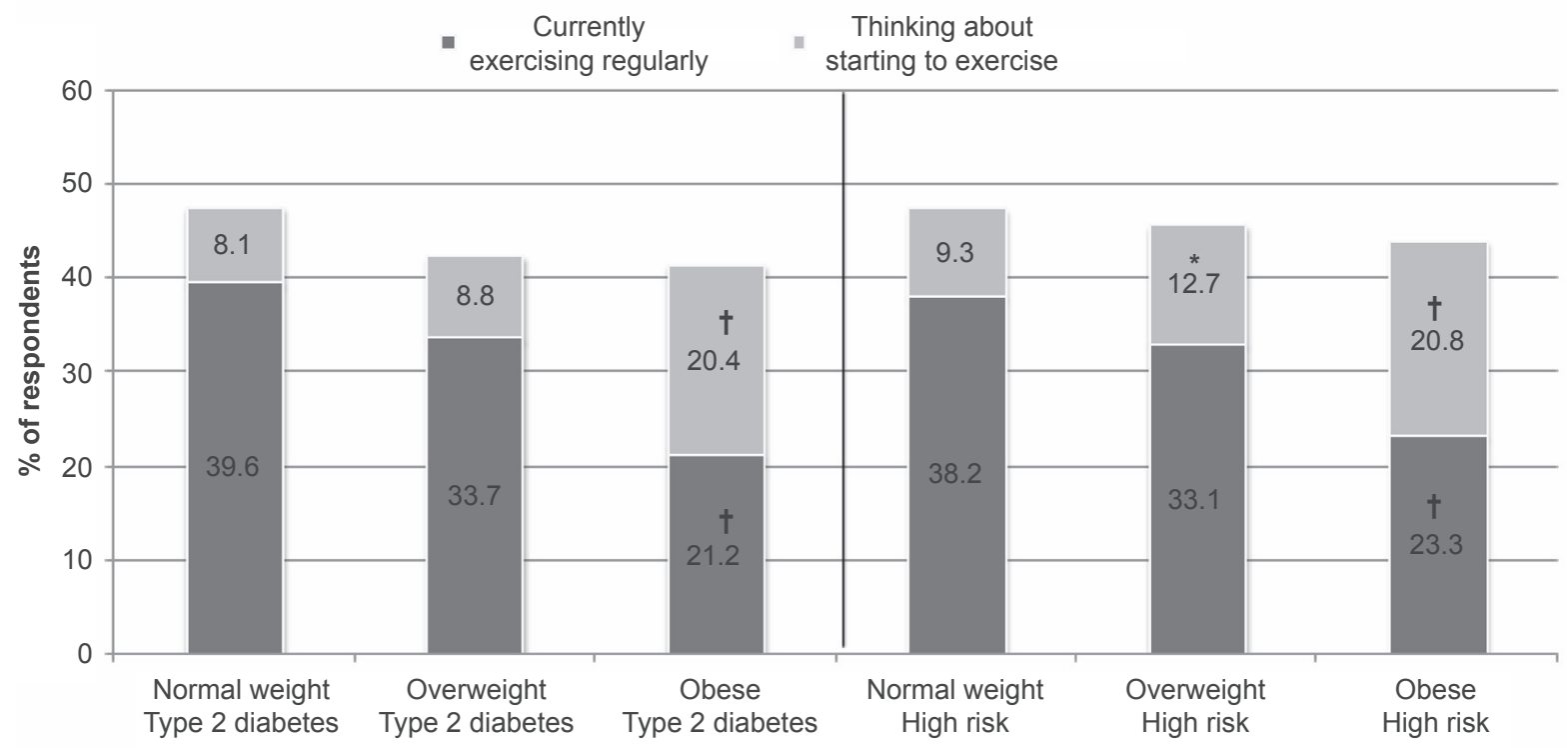

Figure 2 Proportion of respondents currently exercising regularly or thinking about starting to exercise, by body mass index $\left(\mathrm{BMI}, \mathrm{kg} / \mathrm{m}^{2}\right) \mathrm{category}$.

Notes: ${ }^{\dagger} \mathrm{p}<0.001$ across BMI categories within diabetes group; ${ }^{*} \mathrm{p}=0.003$ for comparison of type 2 diabetes mellitus versus high-risk respondents; Underweight/normal weight: BMI < $25.0 \mathrm{~kg} / \mathrm{m}^{2}$; overweight: BMI $25.0-29.9 \mathrm{~kg} / \mathrm{m}^{2}$; obese: BMI $\geq 30.0 \mathrm{~kg} / \mathrm{m}^{2}$. 


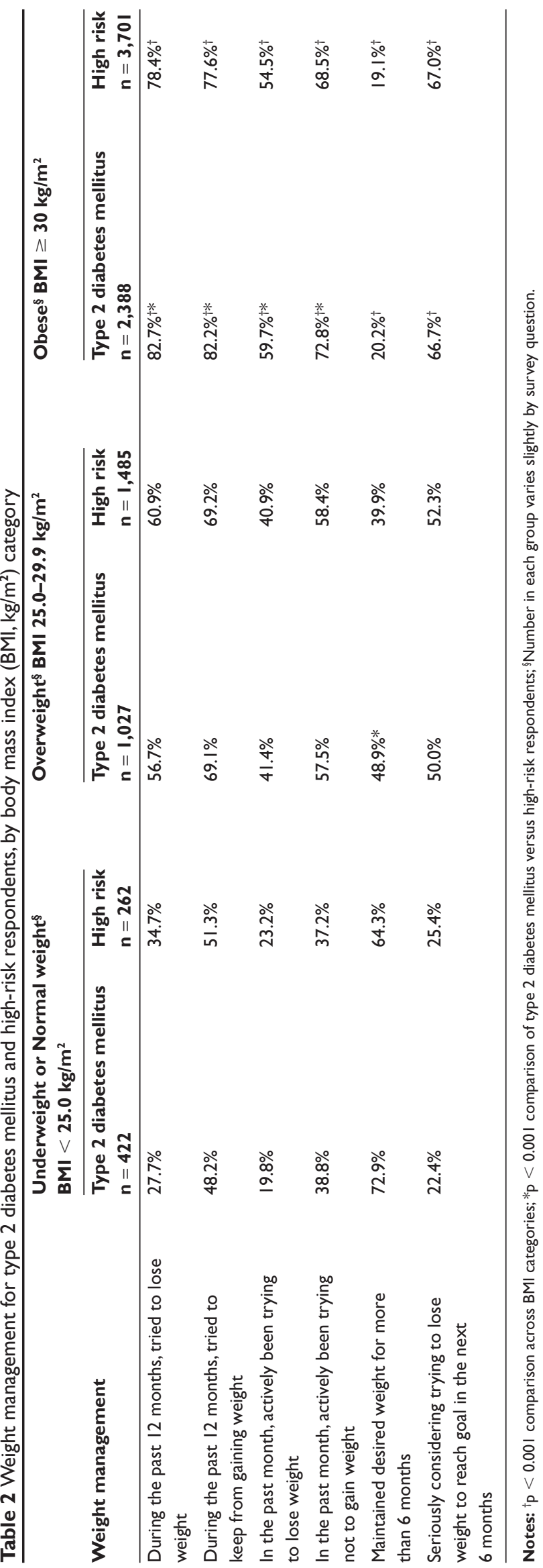

had been advised by their healthcare professional to change their diet and exercise habits, yet they were the least likely to report regular exercise in the past 12 months and the most likely to state that they did not intend to start. ${ }^{7}$ Given the results of the present study and previous investigations, clinicians need to provide more than a recommendation to change behavior and perhaps provide the tools or toolkits to help individuals change behaviors and incorporate exercise and healthier diet into their everyday lives. Materials such as the GAMEPLAN toolkit provided in the "Small Steps, Big Rewards" type 2 diabetes mellitus prevention campaign of the National Diabetes Education Program might prove especially helpful in this area. ${ }^{14}$ Future research should be focused on breaking through the circular pattern of obesity (ie, obese individuals exercise less and this contributes to the progression or maintenance of obesity) and the inability to implement health-promoting behaviors. Research is needed to determine whether regular exercise and weight management can be maintained among diabetes patients so that longterm complications are avoided. Medical efforts now focused on those with diabetes mellitus also need to be focused on those who are overweight or obese, because obese people at risk for diabetes mellitus may be more optimistic about their future health and more able to implement changes. National health policy and educational efforts need to be focused on health attitudes and behaviors that can decrease weight and maintain normal weight to improve health outcomes.

This study provides evidence of the impact of obesity on health attitudes and behaviors in a large sample of type 2 diabetes mellitus and high-risk respondents who are representative of the US population. However, there are limitations to the study that should be considered. Only a small percentage $(5 \%-8 \%)$ of consumers invited to participate in the TNS NFO panel elect to do so, and those who participate are accustomed to completing surveys, leading to the possibility of selection bias. Household panels tend to under-represent the very wealthy and very poor segments of the population and do not include military or institutionalized individuals. These limitations are true for most random sampling and clinically based methodologies. In addition, the determination of type 2 diabetes mellitus and high-risk status was made based upon self-report rather than clinical or laboratory measures for blood glucose, hypertension, cholesterol, height, and weight.

\section{Conclusion}

The diagnosis of type 2 diabetes mellitus was negatively associated with individuals' view of their current health and 
concerns about health in the future. However, differences in concern about future health, exercise and weight management between type 2 diabetes mellitus and high-risk groups were almost entirely explained by BMI differences rather than the presence of diabetes mellitus per se. By the time a person is diagnosed with type 2 diabetes mellitus, they are very likely to be overweight or obese, not exercising and having a difficult time controlling their weight, and showing increased concerns about their future health. Clinicians need to be aware of this impact of obesity when instructing their patients to initiate and maintain healthy behaviors.

\section{Acknowledgments}

Members of the SHIELD Study Group are: Harold Bays, MD, Louisville Metabolic and Atherosclerosis Research Center, Louisville, KY; Debbra D Bazata, RD, CDE, St. Luke's Primary Care South, Overland Park, KS; James R Gavin III, MD, PhD, Emory University School of Medicine, Atlanta, GA; Andrew J Green, MD, Midwestern Endocrinology, Overland Park, KS; Sandra J Lewis, MD, Northwest Cardiovascular Institute, Portland, OR; Michael L Reed, PhD, Vedanta Research, Chapel Hill, NC; Jennifer G Robinson, MD, University of Iowa, Iowa City, IA; and Helena W Rodbard, MD, Rockville, MD. Tina Fanning of Vedanta Research, Chapel Hill, NC, also contributed to this report, performing data collection and analysis.

\section{Disclosure}

SHIELD is supported by funding from AstraZeneca LP. Dr Gavin serves on an advisory board for AstraZeneca LP. Dr Rodbard is an advisor to AstraZeneca LP and served on speakers' bureaus for Abbott, Merck, Novo-Nordisk, Pfizer, sanofi-aventis, and GSK; has served as a consultant for Abbott, Novo-Nordisk, Pfizer, sanofi-aventis, GSK, and Takeda; and has received research grants from Biodel and sanofi-aventis. Dr Fox received support for research and consulting from AstraZeneca LP. Dr Grandy is an employee of AstraZeneca LP.

\section{References}

1. Centers for Disease Control and Prevention. National Diabetes Fact Sheet: General information and national estimates on diabetes in the United States, 2005. Atlanta, GA: US Department of Health and Human Services, Centers for Disease Control and Prevention; 2005.

2. Thom T, Haase N, Rosamond W, et al. Heart disease and stroke statistics - 2006 Update. A report from the American Heart Association Statistics Committee and Stroke Statistics Subcommittee. Circulation. 2006;113: e85-e151.

3. American Diabetes Association. Economic costs of diabetes in the US in 2007. Diabetes Care. 2008;31:596-615.

4. National Center for Health Statistics. NHANES 1988-1994; 2001-2002. Cited Aug 16, 2007. Accessed from: http://www.cdc.gov/nchs/products/ pubs/pubd/hestats/obese/obse99.htm.

5. Thorpe KE. The rise in health care spending and what to do about it. Health Aff (Millwood). 2005;24:1436-1445.

6. Lee Y. The predictive value of self assessed general, physical, and mental health on functional decline and mortality in older adults. J Epidemiol Community Health. 2000;54:123-129.

7. Green AJ, Bazata DD, Fox KM, Grandy S; for the SHIELD Study Group. Health-related behaviours of people with diabetes and those with cardiometabolic risk factors: results from SHIELD. Int $J$ Clin Pract. 2007;61:1791-1797.

8. Bays HE, Chapman RH, Grandy S; for the SHIELD Investigators' Group. The relationship of body mass index to diabetes mellitus, hypertension and dyslipidaemia: comparison of data from two national surveys. Int J Clin Pract. 2007;61:737-747.

9. Bays HE, Bazata DD, Clark NG, et al. Prevalence of self-reported diagnosis of diabetes mellitus and associated risk factors in a national survey in the US population: SHIELD (Study to Help Improve Early evaluation and management of risk factors Leading to Diabetes). $B M C$ Public Health. 2007;7:277.

10. Clark NG, Fox KM, Grandy S; for the SHIELD Study Group. Symptoms of diabetes and their association with the risk and presence of diabetes. Diabetes Care. 2007;30:2868-2873.

11. US Census Bureau. Annual Supplement to the Current Population Survey: Census Bureau Resident Population Estimates of the United States. Washington, DC: US Census Bureau; 2003.

12. American Diabetes Association. Standards of Medical Care in Diabetes-2007. Diabetes Care. 2007;30(S1):S4-S41.

13. Expert Panel on Detection, Evaluation and Treatment of High Blood Cholesterol in Adults. Executive summary of the Third Report of the National Cholesterol Education Program (NCEP) Expert Panel on Detection, Evaluation, and Treatment of High Blood Cholesterol in Adults (Adult Treatment Panel III). JAMA. 2001;285:2486-2497.

14. Small Steps, Big Rewards. Prevent type 2 diabetes. National Diabetes Education Program. Cited Nov 16, 2007. Available from: http://ndep. nih.gov/campaigns/SmallSteps/SmallSteps_overview.htm. 
